\title{
RADAR DIFFRACTION HORIZONS IN SNOW AND FIRN DUE TO A SURFICIAL VERTICAL TRANSFER OF MASS
}

\author{
Jandyr M. Travassos ${ }^{1,5}$, Saulo S. Martins 2,5 , Jefferson C. Simões 3,5 and Webe J. Mansur ${ }^{4}$
}

\begin{abstract}
We focus here on three horizons conspicuously embedded in the rich radar stratigraphy revealed on the fixed-offset radar data obtained in Plateau Detroit, Antarctic Peninsula. Spatial filtering removed the more energetic reflection field and the surface wave arrivals at the earlier time, leaving only the diffracted field. This is particularly striking for the early time horizon where the direct wave arrivals had shrouded the diffractions before filtering. The density estimates and the photographic datasets from a centrally located well at depths compatible with the diffraction horizons suggested they share a common origin: a vertical transfer of mass associated with the formation of surficial hoar from a strong vertical temperature gradient in the snow cover, followed by a quick burial by fresh snow in a high accumulation environment. We have inverted the fundamental mode of the phase velocity dispersion of the surface waves to obtain a group velocity estimate and its depth range, used to improve the 1-D velocity model from a CMP gather by correcting its first velocity estimate. The same inversion solved an apparent ambiguity in our data by associating the surficial horizon with a specific density residual. We have also shown through modeling that the diffraction horizons seen in our data can be explained by the existence of large coarse-grained faceted crystals which became denser with depth than the surrounding firn.
\end{abstract}

Keywords: GPR, radar, diffraction field, velocity model, waveguide, polar stratigraphy, depth hoar, Antarctica.

RESUMO. Concentramo-nos aqui em três horizontes conspicuamente embutidos na rica estratigrafia revelada nos dados de radar de afastamento constante obtidos no Platô Detroit, Península Antártica. Uma filtragem espacial removeu o campo de reflexão mais energético e as chegadas de onda de superfície das primeiras chegadas, deixando apenas o campo difratado. Isso é notável para o horizonte de primeiras chegadas, onde as ondas diretas encobriam as difrações antes da filtragem. As estimativas de densidade e os conjuntos de dados fotográficos do poço localizado no centro da aquisição mostram em profundidades cristais compatíveis com os horizontes de difração dos dados de GPR, sugerindo uma origem comum: uma transferência vertical de massa associada à formação de hoar devido a um forte gradiente vertical de temperatura na cobertura de neve fresca em um ambiente de alta acumulação. Nós invertemos o modo fundamental da dispersão de velocidade de fase das ondas de superfície para obter uma estimativa de velocidade de grupo e sua faixa de profundidade usada para melhorar o modelo de velocidade 1-D a partir de um CMP, corrigindo sua primeira estimativa de velocidade. A mesma inversão resolveu uma ambiguidade aparente em nossos dados ao associar o horizonte superficial a uma densidade específica residual. Também mostramos através de modelagem que os horizontes de difração observados em nossos dados podem ser explicados pela existência de grandes cristais facetados de granulação grossa que se tornaram mais densos com a profundidade do que o firn circundante.

Palavras-chave: GPR, radar, campo difratado, modelo de velocidade, guia de ondas, estratigrafia polar, depth hoar, Antártica.

\footnotetext{
${ }^{1}$ Universidade Federal do Pará, Departamento de Geofísica, Belém, PA, Brazil - E-mail: wavefrontgeo@gmail.com

${ }^{2}$ Universidade Federal Rural do Rio de Janeiro, Departamento de Petrologia e Geotectônica, Seropédica, RJ, Brazil - E-mail: ssmsaulo@gmail.com

${ }^{3}$ Universidade Federal do Rio Grande do Sul, Centro Polar e Climático, Porto Alegre, RS, Brazil - E-mail: jefferson.simoes@ufrgs.br

${ }^{4}$ Universidade Federal do Rio de Janeiro, Lamemo Laboratory, COPPE, Rio de Janeiro, RJ, Brazil - E-mail: webe@coc.ufrj.br

5 INCT da Criosfera
} 


\section{INTRODUCTION}

Radar data has been widely used in mapping spatial distribution of an ice cover properties such as the contact ice-bedrock, the interface between cold and warm ice and the internal layering in snow, firn and ice (Bentley et al., 1979; Clarke \& Bentley, 1994; Arcone et al., 1995; Arcone, 2002; Pälli et al., 2002; Spikes et al., 2004; Dunse et al., 2008; Eisen et al., 2008; Müller et al., 2010; Travassos et al., 2012; Medley et al., 2013; Miège et al., 2013; Koenig et al., 2016). Within snow and firn the mapping is mostly based on changes on density, which translate into the dielectric properties of ice (Looyenga, 1965; Kovacs et al., 1995; Harper \& Bradford, 2003, e.g.). Density is not alone in affecting the radar response, other several factors can affect the dielectric/electric properties of the ice mass, including liquid-water content, chemical composition, microparticle concentration and crystal fabric (Cuffey \& Paterson, 2010).

Density and crystal fabric changes usually occur in association giving rise to important radar reflections belonging to the internal layering in snow and firn. This is the case of melt and depth hoar layers, which may be continuous for long distances, thus becoming useful markers within the ice mass, much like a sulfate-rich layer from a past volcanic event (Cuffey \& Paterson, 2010). Accordingly depth hoar layers may be useful markers within the firn horizon, being uniform across large distances (Arcone et al., 2004, 2005; Helm et al., 2007; Kruetzmann et al., 2011). As such those isochronal markers can be used in extending localized ice core data to far-removed areas.

Solar heating at the near-surface allows the buildup of a strong vertical temperature gradient in the dry snow cover, which gives rise to sublimation, driven by a critical supersaturation of vapor pressure at a given temperature. The vapor moves vertically through the snow overburden and may deposit around centers of crystallization in the form of large faceted crystals (Colbeck, 1983; Alley, 1988; Alley et al., 1990). The kinetic growth of faceted crystals is conditioned by the vertical vapor flux, proportional to the temperature gradient, the larger the latter is, the more rapid the growth and coarse-grained crystals become (Colbeck, 1983, 1987; Alley et al., 1990). All that occurs under an efficient heat change mechanism; sublimation requires a supply of heat whereas deposition releases heat, an exchange of energy accompanying crystal growth.

Depth hoar layers with large coarse-grained faceted crystals develop in autumn as a result of the deposition process of the vapor vertical flux on the immediate overburden in a constructive metamorphism, leading to a continuous growth of facetted ice crystals, with a relatively weak shear strength (Colbeck, 1982, 1983, 1989). The formation process requires the accumulation and burial of depth hoar by fresh snow should occur rapidly, accompanied by a strong negative gradient in temperature (Shuman et al., 1993; Birkeland et al., 1998) so to retain large temperature gradients at depth (Colbeck, 1982). Day-to-day temperature gradients in the range $\gtrsim 5^{\circ} \mathrm{C}$ can reportedly cause near-surface hoar formation (Shuman et al., 1993; Hachikubo \& Akitaya, 1996; Birkeland et al., 1998). The vertical transfer of mass though vapor rising towards the surface should process with a relatively small net loss to the free atmosphere, as compared with the growth and densification rate of the faceted crystals (Alley \& Bentley, 1988; Shuman et al., 1993; Birkeland et al., 1998). With burial a low-density faceted crystals horizon does become denser more rapidly with depth than its surrounding firn horizons (Alley, 1988; Alley \& Bentley, 1988; Alley et al., 1990) thus disrupting the standard monotonically increasing behavior of density with depth (Cuffey \& Paterson, 2010, e.g.).

The physical characteristics a season-related depth hoar horizon favor its radar detectability by more than one reason. Not only a local high-to-low density transition gives rise to a good permittivity contrast but also to a $180^{\circ}$ phase shift on the reflected field, which translates into a polarity change in the radar trace from, say, -+- , to +-+ . Notwithstanding the recognition of a phase anomaly down the trace is anything but easy several authors have used a wavelet polarity change to track a given reflector with fixed-offset data for long distances (Arcone et al., 2004, 2005; Helm et al., 2007). Moreover as hoar crystals have weak lateral strength, the vertical load may be transferred into shear deformation, eventually coalescing crystals into larger blobs, further increasing the chance of detectability of a hoar horizon using the diffracted field. Several works have reported tracing such horizons in radar data along many kilometers (Pälli et al., 2002; Arcone et al., 2004; Richardson-Näslund, 2004; Spikes et al., 2004; Arcone et al., 2005; Helm et al., 2007; Kruetzmann et al., 2011), reflecting a uniform density and crystal fabric horizom in the subsurface.

In this work we analyze radar data obtained on Plateau Detroit, Antarctic Peninsula, a region with a high deposition rate on average of $2.5^{\mathrm{m}_{\text {eca }}} / \mathrm{y}$ (Potocki et al., 2016), about 2.5 times the accumulation rate estimated at Gomez ice core in the south-western Antarctic Peninsula (Thomas et al., 2008). The radar dataset comprises of fixed-offset (F0) and a common midpoint (CMP) gather, complemented with density estimates and photographic data from a well dug during the same field campaign. 

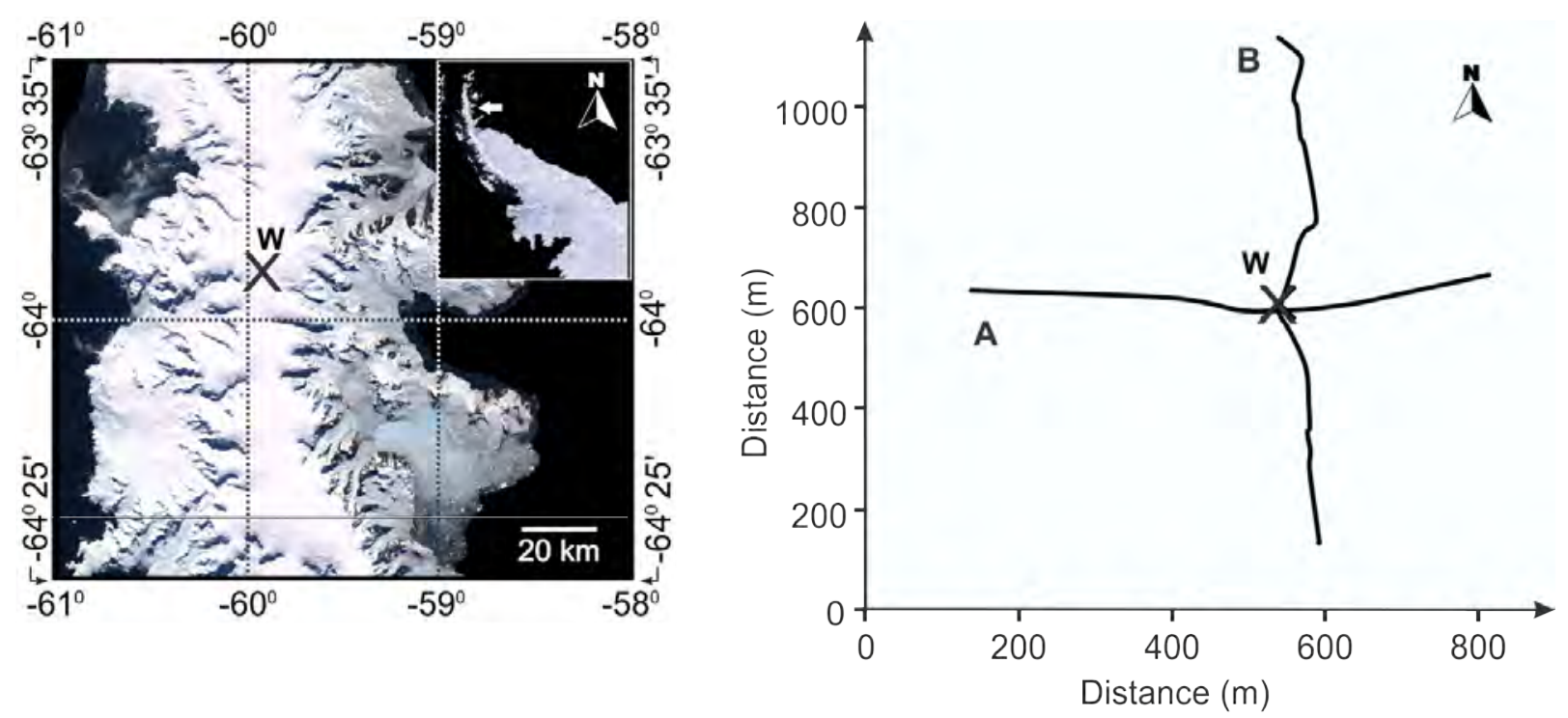

Figure 1 - The $X$ in both panels marks the location of the borehole W, marked on the left on a scene of Landsat Mosaic of Antarctica. The white arrow in the inset indicates the fieldwork location on the Antarctic Peninsula. The right panel shows the two profiles $A$ and $B$ analyzed in this work.

The high snow accumulation results in a rapid burial of relatively thick annual layers turning the area on a privileged location to investigate the layering structure of the firn layer.

We focus here on three diffraction horizons conspicuously seen within the rich radar stratigraphy revealed by two perpendicular FO profiles. The density data associated with the two shallowest horizons indicates they have been formed from a vertical transfer of mass, probably associated with the formation of near-surface hoar. Rather than following the standard approach of using them as isochronal markers as widely reported in the literature we exploit the physical characteristics of those diffraction horizons. Doing so we provide independent data to correct the velocity model estimated from the CMP gather as well as show through modeling, a diffraction horizon seen at depths $\sim 80 \mathrm{~m}$ can be explained by the existence of a horizon of large, centimeter-scale, coarse-grained faceted crystals. Moreover, we have analyzed a surficial graded waveguide created by the mass depletion at the bottom of the first diffraction horizon to estimate a top group velocity at the surface to correct the first velocity estimate from the CMP gather derived 1-D velocity model.

\section{THE DATASET}

The fieldwork was done during summer 2007/2008 on Plateau Detroit (PD) at $64^{\circ} 05^{\prime} 07^{\prime \prime} S, 59^{\circ} 38^{\prime} 42^{\prime \prime} \mathrm{W}$ and $1930 \mathrm{masl}$, on the northern Antarctic Peninsula. Our dataset comprises of GPR and density data, from a borehole. Figure 1 shows the location of the fieldwork superimposed on a Landsat Image Mosaic of Antarctica (LIMA) ${ }^{1}$ of northern Antarctic Peninsula by USGS. LIMA is a true-color, seamless, high resolution (30m) satellite view of Antarctica assembled from more than 1,000 Landsat 7 ETM+ scenes collected primarily during 1999-2003 (USGS - US Geological Survey, 2009).

The radar data comprises of two perpendicular F0 profiles, $A(S-N)$ and $B(W-E)$, crossing each other within their reaches, and one W-E CMP gather. The CMP center point is close to the crossing of the two FO profiles and to the well, W dug during fieldwork, refer to Figure 1. The radar data were collected with a bistatic PULSE EKKO 100 fitted with unshielded $100 \mathrm{MHz}$ antennae in broadside parallel configuration, mounted on a single fiberglass sled. A second, leading, sled transported the radar console and a Leica GPS System 500, completed the man-hauled acquisition train. The time window at acquisition was 3600ns with a temporal sampling rate of 0.9 ns and 8 stacks. A specially built electronic interface fired the GPR at the onset of each GPS NMEA $^{2}$ output message, thus synchronizing trace acquisition to positioning. The spatial sampling varied along profiles, averaging to $0.87 \mathrm{~m}$.

Data processing was restricted to several temporal filtering and gain stages. The original time window used during data acquisition was cut short to $1500 \mathrm{~ns}$ at the processing stage,

\footnotetext{
${ }^{1}$ Scene RGBREF_x-2550000y +1350000 .

${ }^{2}$ Acronym for the National Marine Electronics Association (http://www.nmea.org)
} 

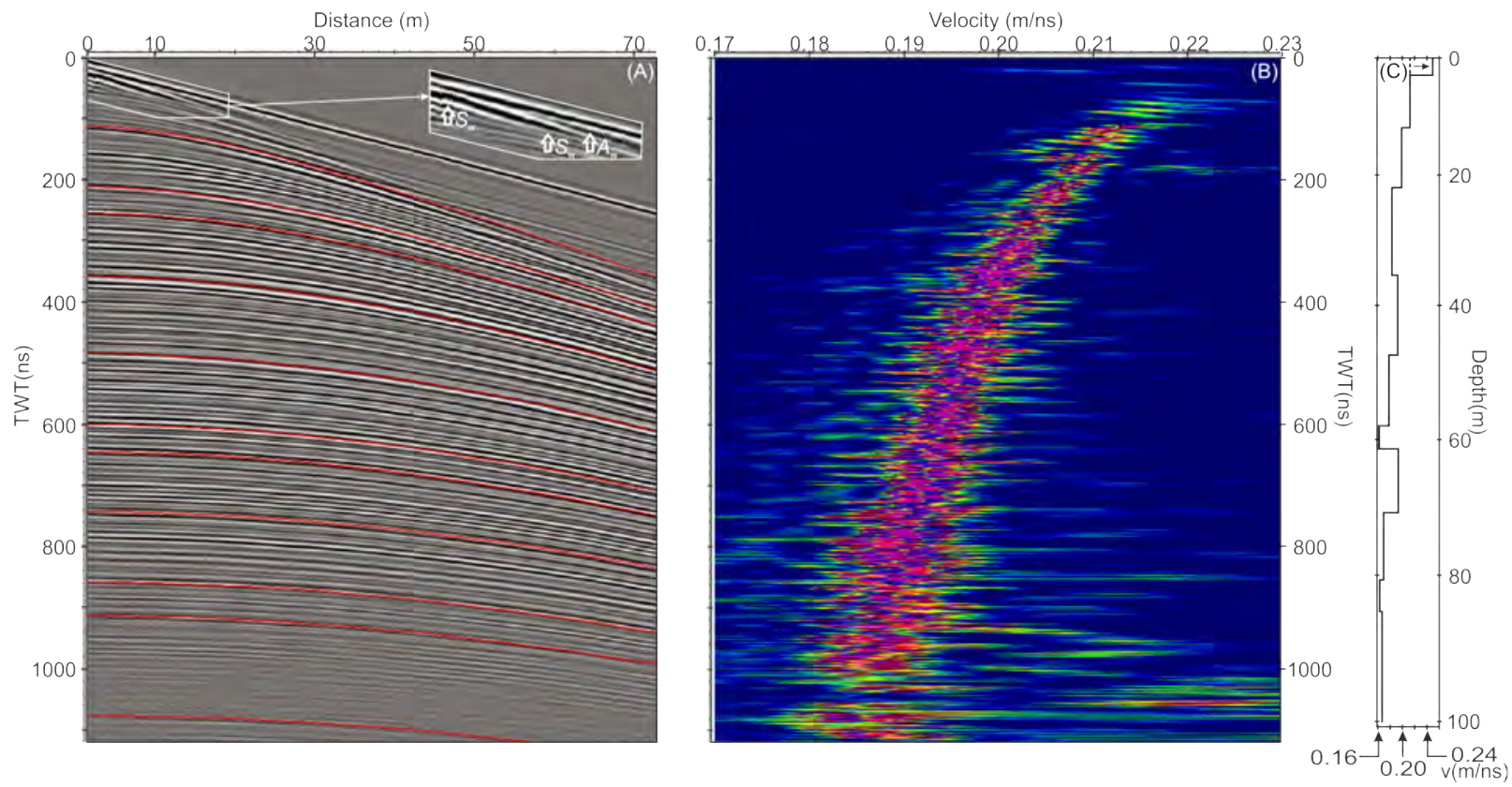

Figure 2 - Panel (A) shows the CMP data with the move outs used for picking on the semblance panel (B) highlighted in red. The inset in (A) shows the direct waves arrivals: the surface wave $S_{w}$ and the airwave $A_{w}$. The white arrow in (B) points to an air reflection from the borehole facility. Panel (C) shows the interval velocity model, the arrow shows the shift on the shallowest part of $v_{1}$ to $\hat{v}(1)$.

corresponding to a depth of $\approx 135 \mathrm{~m}$. From that depth downwards, the section becomes noisier, devoid of reflectors and no return from the bedrock. This means the radar sections are mostly restricted to the snow and firn horizons; the interface between firn and ice was found at $110 \mathrm{~m}$ in the borehole.

\section{The Common Midpoint Data}

The velocity model is estimated from a $\mathrm{W} \leftrightarrow \mathrm{E}$ CMP gather, having a total length of $73 \mathrm{~m}$. We adopted a stop-and-go firing, each antenna being moved away from each other in steps of $0.1 \mathrm{~m}$ from a minimum offset of $1 \mathrm{~m}$. It was not possible to acquire another CMP gather to fathom any lateral changes in firn velocity, plagued as we were by a series of heavy storms during the whole period of our work, leaving us with just a few days worth of data collection. The CMP center point was just a few meters South from the well, enough to prevent the air reflections from its metallic infrastructure affecting too much the radar section (Travassos et al., 2012).

The picking on the velocity spectrum panel produces a root-mean-square velocity model, $v_{r m s, i}, i=1,10$, each estimate being valid above each considered reflector. The $v_{r m s}$ estimates were subsequently inverted to produce the interval velocities estimates through Dix Formula (Yilmaz, 2001), $v_{i}, i=$ $1, \ldots, 10$, shown in panel $\mathrm{C}$ of Figure 2 . We use the $v_{i}$ model to construct the vertical depth axis shown in the figures herein. Note the accuracy of the velocity model, estimated through picking on the velocity spectrum from the CMP, is dependent on gather length and on the subsurface velocity distribution itself. The higher the velocity is, i.e. the closer to the snow surface, the less accurate a velocity estimate is, a fact affecting at least the first estimate $v_{1}$.

We will refine $v_{1}$ in an attempt to reduce the inherent errors in estimating the depth for the radar data using the dispersion of the surface waves traveling along a surficial waveguide. That will split $v_{1}$ into two estimates: $v_{1} \rightarrow \hat{v}_{1}, v_{1}$. The estimate $\hat{v}_{1}$ will be obtained through an inversion process on the dispersion curve of the surface waves below.

\section{The Fixed-Offset Profiles}

We turn our focus to the two F0 profiles, A and B, running W-E and S-N respectively, as shown in Figure 1. Profile A displays a rich stratigraphy along its $683 \mathrm{~m}$ and down to about 1000ns when the signal-to-noise ratio, $\mathrm{S} / \mathrm{N}$, decreases markedly toward the end of the section, refer to Figure 3 . The $1122 \mathrm{~m}$ long profile $B$ displays a similar behavior to profile A, maybe with a slightly better $\mathrm{S} / \mathrm{N}$ with depth, Figure 4 . As the $\mathrm{S} / \mathrm{N}$ deteriorates the signal gets overwhelmed by a grainy looking noise, which we could not filter out without being detrimental to the useful returns. The last 


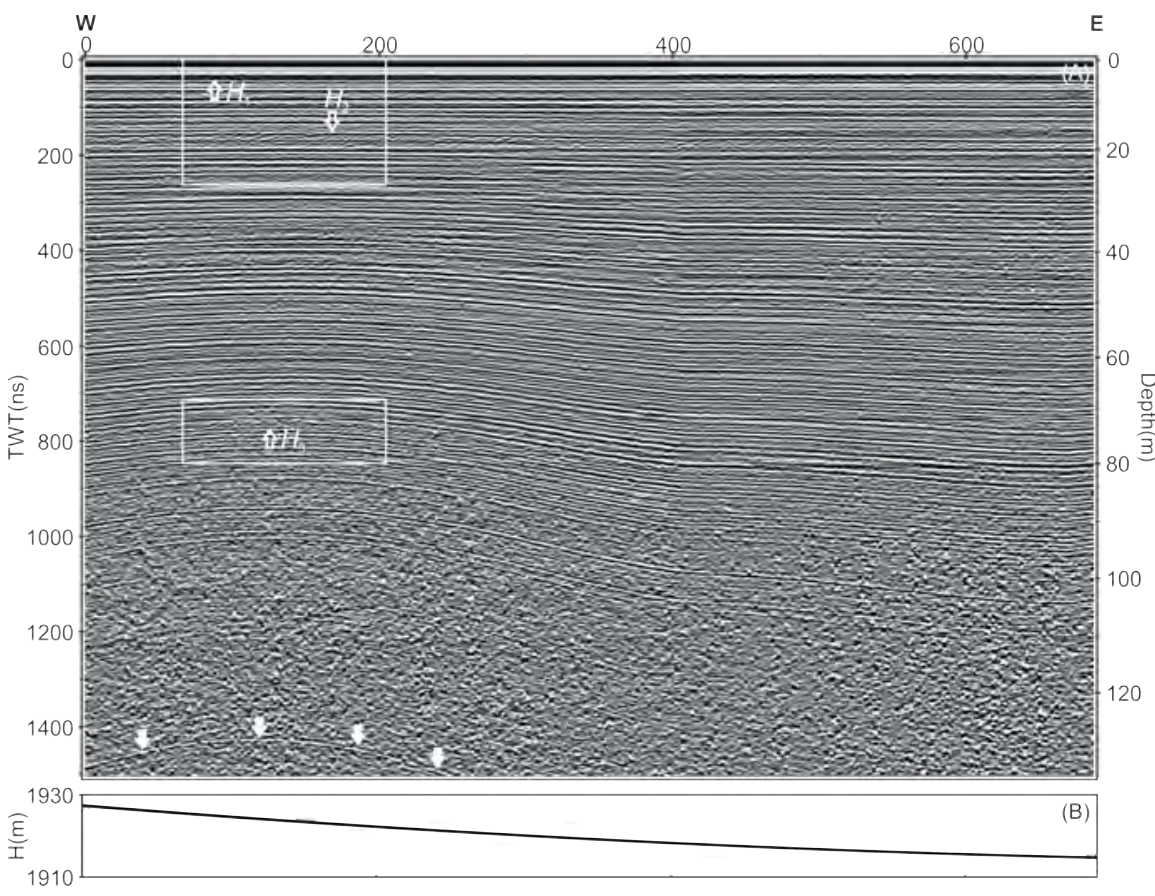

Figure 3 - The radar section of profile A with the vertical axes showing both TWT and depth, as estimated by the 1-D velocity model is shown in Figure 2 . The two white rectangles delimitate parts of the section with the diffraction horizons $H_{i}, i=1,2,3$, indicated by hollow white arrows. The solid arrows point to the deepest reflector seen in the section.

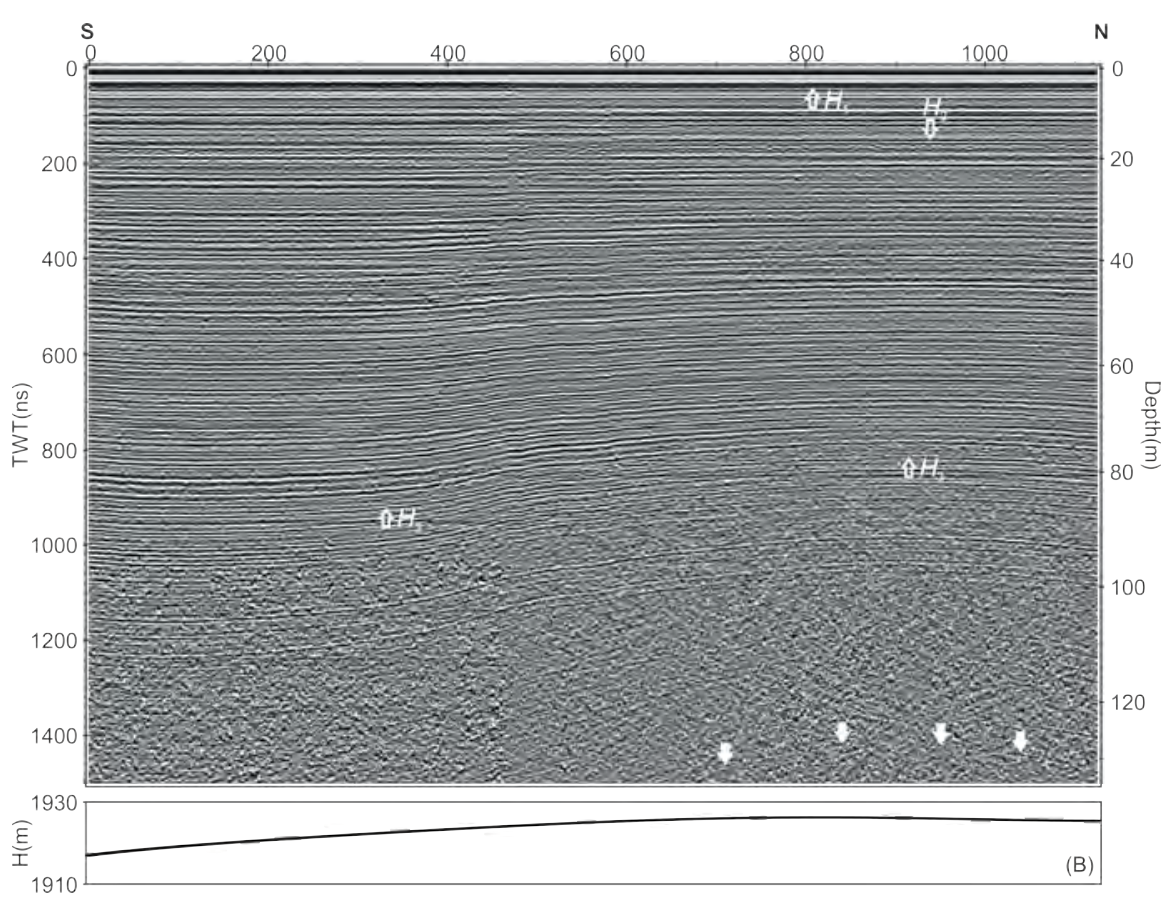

Figure 4 - The radar section of profile B with the vertical axes showing both TWT and depth, the latter estimated by the 1-D velocity model shown in Figure 2 . The hollow white arrows point to the diffraction horizons $H_{i}, i=1,2,3$. The solid arrows point to the deepest reflector seen in the section. 
reflector we were able to recover lies at TWT $>1400 \mathrm{~ns}$, refer to Figures 3 and 4 . We did not correct for the topography of $\approx 3 \%$ any of the two sections, as we are not interested in near-surface accumulation rates.

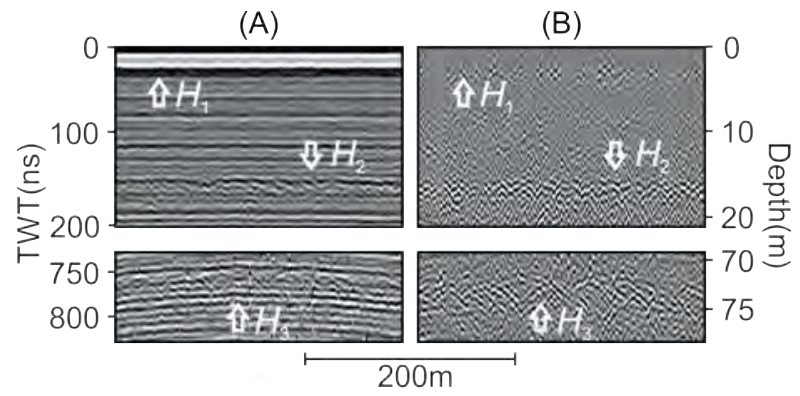

Figure $\mathbf{5}$ - Panels (A) show parts from the radar section of profile $A$ within the two white rectangles shown in Figure 3. Panels (B) show the corresponding diffracted fields obtained from trace differencing.

Both profiles begin with an energetic band of the two direct arrivals at an early time, followed by many energetic reflectors with increasing dips the greater the TWT is. Notwithstanding the rich firn stratigraphy, revealed in Figures 3 and 4, we rather focus on the three horizons $H_{i}, i=1,2,3$, which appear arrowed in the sections. Horizon $H_{1}$ shows the direct air and ground waves arrivals, bundled as a relatively thick black and white horizontal band at $\leq 30 \mathrm{~ns}$. The other two horizons are characterized by many diffractions bounded by strong reflectors in both sections. $\mathrm{H}_{2}$ is horizontal at TWT $\approx 160 \mathrm{~ns}$, while $\mathrm{H}_{3}$ dips in both sections. Diffractions in $H_{3}$ are a little fainter than in $H_{2}$ but still noticeable.

We can separate the diffractions from the other more energetic direct and reflected waves in horizon $H_{1}$, through spatial high-pass filter, trace differencing, thus yielding just the diffracted field. The spatial filter gives better results the flatter a given horizon is. The Figure 5 compares the full with the diffracted fields inside the white rectangles of Figure 3 . The diffractions in $H_{1}$, which were hitherto overwhelmed by the energetic direct waves arrivals now appear clearly. Accordingly, we can hypothesize all three horizons share similar causes.

The inquisitive reader will not have to strain his eyes in realizing there are other additional diffraction horizons seen in the data, for instance, it is easy to spot two such horizons between $H_{1}$ and $H_{2}$ in Figure 5. We choose to keep our focus on the three horizons mentioned above as they provide us with the information we need.

\section{The Density Record}

We dug a $133 \mathrm{~m}$ deep borehole at the center of the study area, which yielded intact ice cores down to $109.29 \pm 0.49 \mathrm{~m}$ where brittle ice has begun. From that depth onwards all but just one ice core surfaced completely fractured, probably from the release of stresses present in the ice during the coring activity. The drilling tool finally got stuck at $133.28 \mathrm{~m}$, bringing the drilling effort to a halt. We deal here on the ice density data, which is limited in depth to $65 \mathrm{~m}$ only; the remaining data was regrettably lost. We have estimated one density value for each ice core with a modal length of $0.98 \mathrm{~m}$, resulting in a standard, monotonically increasing data series with depth, e.g. (Cuffey \& Paterson, 2010).

The depth dependency on the density estimates can be expressed as a deviation from the density of pure glacier ice $\rho_{\text {ice }}$ (Herron \& Langway Jr, 1980),

$$
\frac{d \rho(z)}{d z}=C_{0}\left(\rho(z)-\rho_{\text {ice }}\right) .
$$

A solution to (1) is $\rho(z)=C_{1}+C_{2} \exp \left(C_{0} z\right)$, where the $C_{i}, i=$ $0,1,2$, are constants. This empirical model of firn densification ranges from the surface to the zone of pore close-off, including two (Herron \& Langway Jr, 1980) or even three (Ligtenberg et al., 2011) distinct stages of firn densification. To our ends it is enough to approximate the density log with one single densification stage throughout the complete depth range,

$$
\rho(z)=0.339 z^{0.185} \quad \text { for } z \leq 65 \mathrm{~m} \quad\left(R^{2}=0.97\right) .
$$

In spite of its simplicity relation (2) serves well the purpose of removing the depth dependence on the density, leaving only localized variations of density estimates, or residuals $\delta \rho(z)$. Consider an anomalous residual if it stands more than two standard deviations away from the expected firn densification, expressed by relation (2): $|\delta \rho(z)|>0.029$. Of the four anomalous residuals, $\delta_{i}, i=1, \ldots, 4$, only $\delta_{4}$ is a positive, or denser, residual. The density estimates and relation (2) are shown in Figure 6.

$\delta_{1,2,3}$ are negative residuals indicative of mass depletion, probably due to a process of vapor flux loss to the atmosphere and the formation of near-surface hoar (Birkeland et al., 1998; Shuman et al., 1993). With burial that hoar horizon does become denser more rapidly with depth than its surrounding firn horizons, the lower horizon becoming noticeably lighter due to the mass loss. This denser-to-light firn couplet is not seen in in the density data in Figure 6 due to the density data discretization, it rather manifests as negative residuals in density, probably due to the fact the mass loss affects a wider depth span than the more limited thickness of a hoar horizon. 


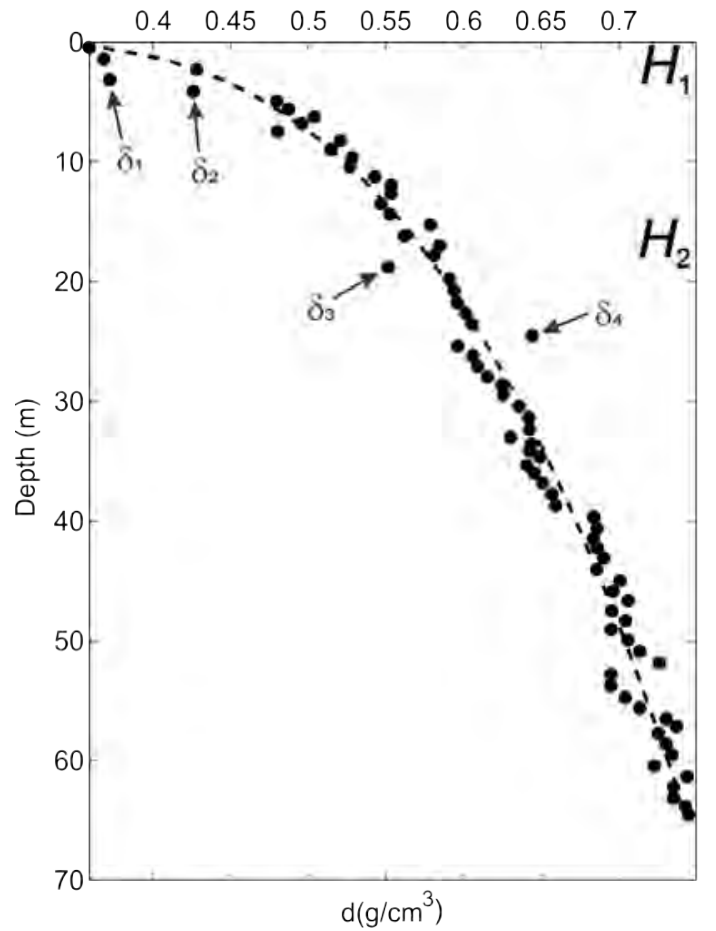

Figure $\mathbf{6}$ - The heavy dots are the density estimates as measured along the well $W$. The dash line shows the expected densification of firn with respect to depth, relation (2). The density estimates corresponding to the anomalous residuals, $\delta_{i}, i=1, \ldots, 4$ are indicated by arrows. The depths of the two horizons $H_{1}$ and $\mathrm{H}_{2}$ are depicted close to the right vertical axis.

The residuals $\delta_{1,2,3}$ occur at depths compatible with the first diffraction horizon $H_{1}$, while $\delta_{3}$ virtually coincides in depth with $H_{2}$ at $19 \mathrm{~m}$, Figure 6 . The two residuals $\delta_{1,2}$ occurring at depths close to a single diffraction horizon $H_{1}$ is less an ambiguity than it may appear at first glance as $H_{1}$ occurs at an early time, where the velocity model is less accurate. We are going to come back to this below when we refine the earliest time velocity estimate $v_{1}$.

Conversely, the positive anomalous residual $\delta_{4}$, at $\sim 25 \mathrm{~m}$, is too far in TWT from the nearest anomaly $H_{2}$, even considering eventual velocity model inaccuracies. Therefore, Figure 6 suggests that horizons $H_{1}$ and $H_{2}$ are correlated with the negative density residuals. This implies the horizons $H_{1}$ and $H_{2}$, associated as they are to $\delta_{1,2,3}$, are geophysical signatures of a process of mass depletion associated to a vertical flux of vapor from sublimation, subsequently deposited within an overlying horizon. On the other hand, $\boldsymbol{\delta}_{4}$ probably would have required the onset of surface melting followed by refreezing. In any case, both mechanisms would need the occurrence of intense temperature gradients in past climate.

\section{THE DIFFRACTION HORIZONS $H_{1}, H_{2}$ AND $H_{3}$}

We now focus on the three geophysical horizons $H_{1,2,3}$, which thanks to the spatial high-pass filter we know they are all characterized as horizons of diffractions. Before filtering the diffractions in $H_{1}$ were hidden behind the direct waves arrivals, refer to Figure 5. Moreover, horizons $H_{1,2}$ may be associated with three negative residuals $\delta_{1,2,3}$, all indicative of a vertical transfer of mass from a particular horizon to the overburden or to the atmosphere. The diffractions seen in $H_{1,2,3}$ may be explained by a rapid densification of a low-density hoar horizon with depth (Alley, 1988; Alley \& Bentley, 1988).

\section{The Surficial Waveguide $H_{1}$}

The direct waves arrivals of horizon $H_{1}$ span from the surface to a TWT $=25 n$ s, which by using the first velocity estimate $v_{1}=$ $0.2 \mathrm{~m} / \mathrm{ns}$ valid for TWT $\leq 250 \mathrm{~ns}$, would imply in a depth of $3 \mathrm{~m}$. As the discretization of the density estimates origins from a core length with a modal length of $0.98 \mathrm{~m}$, the two density residuals $\delta_{1}$ and $\delta_{2}$ are limited in depth to $<4 \mathrm{~m}$, under the reach of two ice cores with half-lengths at depths of 2.28 and $3.16 \mathrm{~m}$.

There are many examples of formulae relating density to permittivity/velocity (Looyenga, 1965; Kovacs et al., 1995; Harper \& Bradford, 2003). Any of them would suit us in estimating a permittivity contrast between two ice cores around $\delta_{2}$ based on the density record. From Looyenga (1965) we estimate an 8.7\% contrast in permittivity, enough to yield a critical angle across the transition boundary. This ensures that a great part of the energy will be partly confined within the top layer, acting as a planar asymmetrical waveguide of about $<4 \mathrm{~m}$ thick, bounded by air on its top boundary and less refringent ice on its bottom. That is a graded waveguide as the permittivity varies inside it and thus internal reflections and refractions, but for our purposes, we can simply ignore those internal phenomena.

Our model for the waveguide has three homogeneous, stationary and nonmagnetic media with the following hierarchy on the real permittivities: $\varepsilon_{1}<\varepsilon_{2}>\varepsilon_{3}$. This represents a transition from a less refringent air layer $\left(\varepsilon_{1}=1\right)$ to a more refringent/denser firn layer, on the top of a less refringent/lighter firn half-space. The geometry of the system can be parameterized using a Cartesian reference frame with the $z$-axis pointing downwards having the origin at the snow surface where the transmitter and receiver set, with the $x$-axis pointing along the direction of increasing offset, in accordance to the CMP gather. The layer is infinite along both $x$ and $y$ axes so there will be neither reflections nor edge effects to deal with along 
those two directions. The EM waves are launched into the waveguide by the bipolar transmitting antennae, perfectly coupled to the waveguide's free interface. As the antennae were deployed in broadside-perpendicular configuration during fieldwork, i.e. perpendicular to the $x$-direction, the problem is restricted to the TE mode.

The waveguide acts as a directional filter, allowing rays with angles $\theta_{z} \geq \theta_{c}$ reach larger offsets, tipping the energy balance more and more toward rays traveling with larger angles, at larger offsets. Energy losses occur within the waveguide through a combination of diffraction, geometric wavefront spreading and absorption in the medium, the former being the main energy loss mechanism. All occurs as if a net purely horizontal field propagated along the increasing offset direction with a wave number

$$
k_{x}=\frac{2 \pi}{\lambda_{2}}=\frac{2 \pi f}{v_{p(\Phi)}}
$$

where $\lambda_{2}$ is the wavelength inside the waveguide, $f$ is the frequency and $v_{p}(\Phi)$ is the phase velocity, function of the phase difference $\Phi$ of waves traveling along the waveguide. The $k_{x}$, real in lossless media, has the same value across both boundaries due to the continuity of the parallel field components.

The propagation modes along the waveguide are conditioned by the total phase difference at a given offset $x_{i}$. We can write the phase difference after a given ray have reflected back into the waveguide as

$$
\Phi_{i}=\left(\Phi_{23}+\Phi_{21}\right)_{i}
$$

where $\Phi_{2 i}$ is the phase of a wave zigzagging along the waveguide, medium 2 after it has bounced off from the interface with any of the two boundary media $i \neq 2$. The waves interfere constructively after successive reflections, making the propagation modes a waveguide's static property. A modal propagation can only exist above a cutoff frequency, which is distinct for each mode (Lorrain et al., 1988).

The modal equation for our system is (Lorrain et al., 1988, Chapter 35)

$$
4 \pi \frac{r}{\lambda_{2}} \cos \theta=\Phi_{21}+\Phi_{23}+2 m \pi
$$

where $r$ is the waveguide thickness. This is an eigenvalue equation for the angle of incidence $\theta$ on a given interface. The phase difference $\Phi$ is a function of $\theta$, which can only attain values satisfying the modal equation (5), each integer $m$ corresponding to an eigenvalue of $\theta$ and to a given propagation mode; $m$ is the mode order. From relation (3) the phase velocity in the waveguide can be expressed as

$$
v_{p}(\Phi(\theta))=f \lambda_{2}=\frac{c}{\sin \theta \sqrt{\varepsilon_{2}}} .
$$

Apply f-k filtering to the CMP data to yield a section where the direct wave arrivals become dominant. Clean the section by muting the air arrivals above and filter the artifacts below the direct ground wave arrivals. Produce a phase velocity spectrum (Park et al., 1998) and pick the propagation modes. Note that a phase velocity dispersion curve could have also been obtained directly from the f-k spectrum (Strobbia \& Cassiani, 2007). Figure 7 show the phase velocity panel conspicuously showing 4 propagation modes, corresponding to $m=1, \ldots, 4$ in equation (5), along with their respective pickings.

We invert the phase velocity dispersion curve corresponding to the fundamental mode of the TE mode, $m=1$ in equation (5), which is the curve labeled 1 in Figure 7 . The direct model is a multi-argument function $v_{p}(\Phi)=\left(f, \theta, \varepsilon_{2}, \varepsilon_{3}, r\right)$, from equations (5) and (6). We regularize the inversion procedure by restricting parameter ranges to $\varepsilon_{2}=[1.33,1.86]>\varepsilon_{3}=$ $[1.33,1.99], r=[0.5,6] \mathrm{m}$. We consider the inversion problem have converged when the L1 norm cost function on the phase velocity

$$
\Psi=\frac{1}{N} \sum_{i=1}^{N}\left|\frac{\hat{v}_{p}\left(f_{i}\right)-v_{p}\left(f, \theta, \varepsilon_{2}, \varepsilon_{3}, r\right)}{\hat{v}_{p}\left(f_{i}\right)}\right|,
$$

estimated for the $N$ picked frequencies, reaches its global minimum. $\hat{v}_{p}$ is a picked value and $v_{p}$ is estimated through the modal equation (5). We use a local minimization algorithm based on the simplex search method to find the minimum of (7).

Figure 8 shows the mapping of the cost function (7) for the whole allowed range of the parameters $\left(\varepsilon_{2}, \varepsilon_{3}, r\right)$. The cost function reaches a single, conspicuous, minimum pointing to an inverted surficial waveguide characterized by a permittivity of $\varepsilon_{2}=1.39$ and a thickness of $r=2.5 \mathrm{~m}$. The inverted thickness of $r=2.5 \mathrm{~m}$ indicates that the horizon $H_{1}$ originates at the depth corresponding to the density residual $\delta_{2}$ at depth of $\leq 3 \mathrm{~m}$. Considering that the density discretization comes from ice cores with a modal length of $0.98 \mathrm{~m}$ the agreement of our inversion to the observed data is remarkable.

We incorporate $\varepsilon_{2}$ in our 1-D velocity model shown in Figure 2 using relation (8) and substituting the first $r=2.5 \mathrm{~m}$ of the estimate $v_{1}$ by $\hat{v}_{1}=0.25 \mathrm{~m} / \mathrm{ns}$, as shown in Figure 2. With this correction we can now associate the bottom boundary of $H_{1}$ with the ice core at a half-core depth of $3.16 \mathrm{~m}$. This associates 


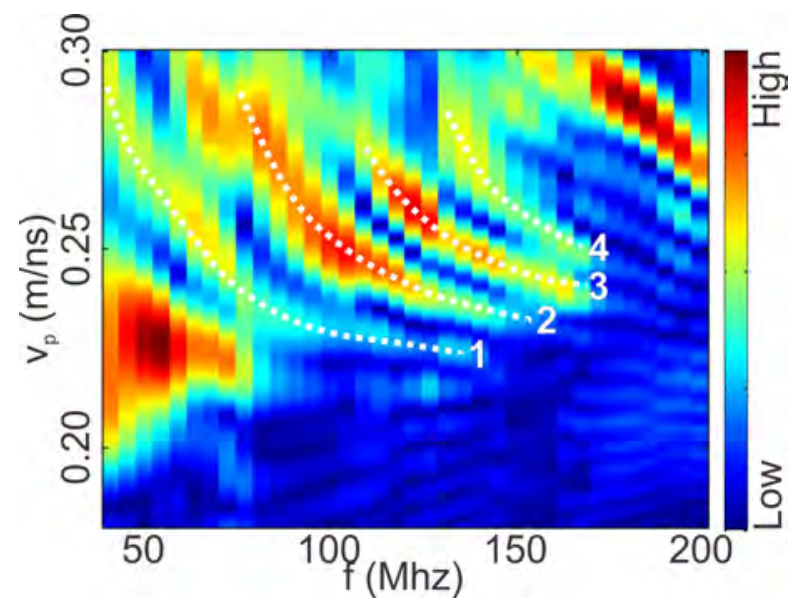

Figure 7 - Phase velocity spectrum for the dispersive direct ground wave arrivals, showing the maxima corresponding to the first 4 modes. The picking on the velocity dispersion curves is represented by the four white dash curves.

$H_{1}$ to the density residual $\delta_{1}$, thus solving the open issue above in the section on the density data.

\section{Modeling the Diffraction Horizons $\mathrm{H}_{1}, \mathrm{H}_{2}$ and $\mathrm{H}_{3}$}

The diffraction horizons seen in our data could have been produced by rough interfaces or individual bodies, all of limited extent as compared to the wavelength. Fractures can also produce diffractions, but they cannot be confined to relatively thin horizons. Ice core inspection revealed a few rough surfaces only on the top $r=15 \mathrm{~m}$ after that surfaces tended to be flat. It remains to us checking whether large hoar crystals can produce the diffractions we see in our data even down to a depth of $\simeq 80 \mathrm{~m}$.

We resort to numerical modeling to access whether large crystals can indeed produce the conspicuous geophysical signatures seen in our data. We assess their size resorting to photographs of thin sections of the ice cores with crossed polarizers at depths compatible to the depths of the diffraction horizons $H_{1}, H_{2}$ and $H_{3}$. Grains of dissimilar orientations will appear with different colors under the crossed polarizers due to the optical birefringence of ice. Their visibly etched boundaries structures become aligned to a given axis orientation under the polarizers, thus allowing counting and size estimation.

We cut $1 \mathrm{~mm}$ thick sections of the ice cores both parallel and perpendicular to the core's Iongitudinal axis. Each section is laid on a universal stage and photographed with a digital camera under polarizers with relative angles $0^{\circ}, 30^{\circ}, 45^{\circ}, 60^{\circ}$

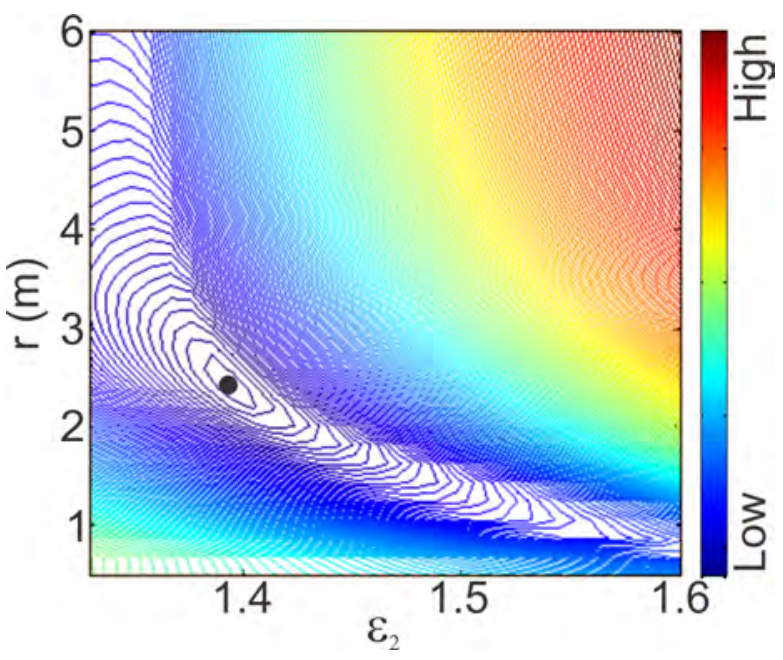

Figure 8 - Mapping of the cost function (7) for the whole allowed range of the parameters $\left(\varepsilon_{2}, \varepsilon_{3}, r\right)$. The black dot shows the position of the global minimum.

and $90^{\circ}$. The varying lateral dimensions of the sections are the function of the brittleness of firn, being always $\leq 9 \mathrm{~cm}$ and $\leq 7 \mathrm{~cm}$, respectively. Figure 9 shows photographs from two ice cores at depths compatible to the geophysical anomalies $\mathrm{H}_{2}$ and $H_{3}$, respectively. The vertical and horizontal cuts have the same polarization angle for the crossed polarizers. The boundaries between the large crystals and the smaller rounded equilibrium firn crystals, which high accumulation areas firn grains can be modeled as prolate spheroids with an axial ratio $\approx 1$ (Alley, 1987), are clearly visible in the axis parallel to core sections. The firn round grains appear less bright as they scatter light incoherently. The large crystals can be $\gtrsim 2 \mathrm{~cm}$ at $15 \mathrm{~m}$ deep, while smaller crystals of $\simeq 1 \mathrm{~cm}$ parallel and $\simeq 0.5 \mathrm{~cm}$ perpendicular to core axis are seen within the $95 \mathrm{~m}$ depth interval.

Construct a three-layer model with three horizons of little spheres to simulate the large crystals and use the GprMax software (Giannopoulos, 2005). The three-layer model is inspired by the interval velocity model shown in Figure 2, the permittivity of each layer is given by

$$
\varepsilon_{i}=\left(c / v_{i}\right)^{2} .
$$

where $c=0.3 \mathrm{~m} / \mathrm{ns}$ is the velocity of light, and $v_{i}, i=1,2,3$ are the velocities of each layer with bounds $H_{i}^{t}$ and $H_{i}^{b}$. The depths to the spheres horizons, $H_{i}^{s}$ in each layer are compatible with the diffraction horizons seen in our data. The first horizon has just 1 row of spheres, the other two have two vertically contiguous rows, with centers laterally dislocated in relation to the other row. 
All the spheres have the same diameter $\phi=0.025 \mathrm{~m}$, a compromise between the observed grain sizes and numerical issues. The model simulates a fixed-offset profile with antennae offset of $0.5 \mathrm{~m}$ and a spatial sampling of $\Delta x=0.02 \mathrm{~m}$, for a maximum depth of $90 \mathrm{~m}$, corresponding to a time window of $1017 n s$. In order to attribute a permittivity value $\varepsilon_{i}^{s}$ to the spheres we resort to the experimental fact the radar velocity through snow, firn and ice can be related to density. We adapted the formula of Looyenga (1965) to our density data to estimate the permittivity of the spheres. All the model parameters we used in generating the synthetic data are listed in Table 1.

Table 1 - Model parameters used in constructing a three-layer model, each having little spheres along horizons. Each sphere horizon $H_{i}^{s}$ is made up of one $[\cdots]$ to two rows $[\because]$ of spheres.

\begin{tabular}{|clc|}
\hline$\varepsilon_{i}$ & $H_{i}^{t}, h_{i}^{b}(\mathrm{~m})$ & $H_{i}^{s}(\mathrm{~m}), \varepsilon_{i}^{s}$ \\
\hline$\varepsilon_{1}=1.7$ & {$[0,3.5)$} & $H_{1}^{s}=3, \varepsilon_{1}^{s}=1.53[\cdots]$ \\
$\varepsilon_{2}=2.25$ & {$[3.5,33)$} & $H_{2}^{s}=16, \varepsilon_{2}^{s}=2.14[\because]$ \\
$\varepsilon_{3}=2.49$ & {$[33,90]$} & $H_{3}^{s}=80, \varepsilon_{2}^{s}=2.14[\because]$ \\
\hline
\end{tabular}

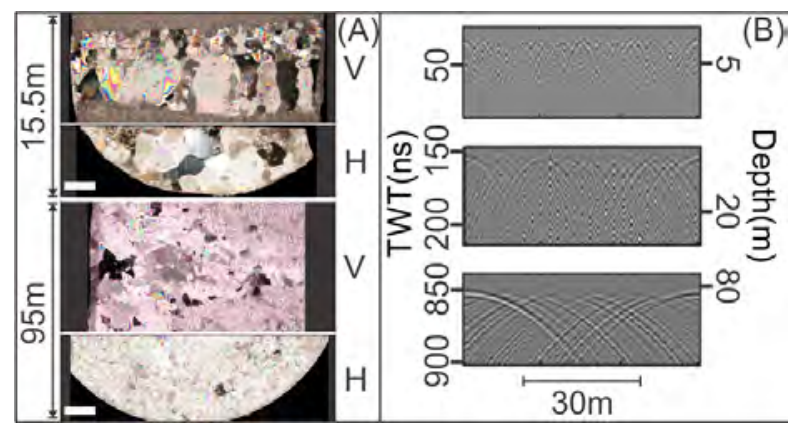

Figure 9 - Panel (A) shows photographs of vertical (V) and horizontal $(H) 1 \mathrm{~mm}$ thick cuts at two depths. The two horizontal white segments on the left lower corner represent $1 \mathrm{~cm}$. Panel (B) shows a stack of horizons cut from the numerical data cut at the depths of the spheres horizons.

We apply a trace-difference filter to the synthetic data to enhance the hyperbolic and suppress the horizontal events, resulting in an all-blank section but for the diffractions. We present the results in Figure 9 as a stack of radar section cuts at the spheres horizons, each having an independent gain level for the sake of visualization. The synthetic data tells us that large crystals can indeed produce the diffractions seen in our data even at great depths $\simeq 80 \mathrm{~m}$. And as the kinetic growth of hoar crystals results from the occurrence of intense temperature gradients, then the three diffraction horizons $H_{1,2,3}$ can be regarded as markers in radar sections, linked to the past climate.

\section{CONCLUSIONS}

We have analyzed three diffraction horizons $H_{1,2,3}$ in a radar F0 dataset obtained in a high accumulation region of northern Antarctic Peninsula. Density and photographic data from a well dug in the same field campaign complemented the geophysical data. We worked with the hypothesis that those horizons are a geophysical signature of vertical transfer of mass, probably associated with the formation of near-surface hoar, subsequently quickly buried by fresh snow in a high accumulation context. Hoar horizons are used at large as chronological radar markers much like, e.g., past volcanic event fallout.

We have separated the weaker diffracted field in the first diffraction horizon $H_{1}$ by filtering off the more energetic surface wave arrivals, showing that horizon has diffractions like the other two horizons. Because that horizon is bounded by air on its top boundary and less refringent ice on its bottom, it acts as a planar asymmetrical waveguide, appearing in the CMP gather as surface waves dispersive arrivals. We have inverted the fundamental mode of phase velocity dispersion to obtain both a surficial group velocity estimate and the waveguide thickness. The inversion results were used in correcting the first velocity estimate from the CMP-derived 1-D velocity model, thus improving the accuracy of the time-to-depth transformation of the radar data. The improved depths allowed to associate the first diffraction horizon $H_{1}$ to the specific density residual $\delta_{1}$, thus solving an apparent ambiguity in our dataset. To our knowledge our work is the first to correct a CMP velocity model with a group velocity estimate from the inversion of the phase velocity dispersion of the surface wave arrivals.

Our results allowed the association of the two shallowest diffraction horizons to anomalous negative residuals in density, indicative of mass depletion probably due to a process of vapor flux losses to the overburden and to a lesser extent to the atmosphere. Notwithstanding the third horizon lying beyond the deepest density estimate, we can assume it shares the same origin, primarily related to strong temperature gradients. To show that we resorted to numerical modeling to show the diffraction horizon seen at depths $\sim 80 \mathrm{~m}$ probably originate from centimeter-scale grains; they cannot be explained by the usual firn round grains otherwise they would be seen everywhere throughout our data, not confined to horizons. Those large coarse-grained faceted crystals are typical of the kinetic growth 
of depth hoar and, therefore are associated with large temperature gradients.

\section{ACKNOWLEDGMENTS}

The authors thank the Instituto Antártico Chileno (INACH) and the Chilean Air Force (FACH) for their invaluable help during fieldwork. The optical data on the ice core sections were obtained in the Cold Lab of the Climate Change Institute, University of Maine, Orono, USA. The fieldwork was fully supported by the Brazilian Antarctic Program (PROANTAR), through the CNPq and CAPES. Authors thank an anonymous reviewer whose comments and suggestions helped to improve and clarify a great deal this manuscript.

\section{REFERENCES}

ALLEY RB. 1987. Texture of Polar Firn for Remote Sensing. Annals of Glaciology, 9: 1-4. doi: 10.3189/S0260305500200670.

ALLEY RB. 1988. Concerning the Deposition and Diagenesis of Strata in Polar Firn. Journal of Glaciology, 34(118): 283-290. doi: 10.3189/ S0022143000007024.

ALLEY RB \& BENTLEY CR. 1988. Ice-Core Analysis on the Siple Coast of West Antarctica. Annals of Glaciology, 11: 1-7.

ALLEY RB, SALTZMAN ES, CUFFEY KM \& FITZPATRICK JJ. 1990. Summertime formation of depth hoar in central Greenland. Geophysical Research Letters, 17(13): 2393-2396.

ARCONE SA. 2002. Airborne-radar stratigraphy and electrical structure of temperate firn: Bagley Ice Field, Alaska, USA. Journal of Glaciology, 48(161): 317-334.

ARCONE SA, LAWSON DE \& DELANEY AJ. 1995. Short-pulse radar wavelet recovery and resolution of dielectric contrasts within englacial and basal ice of Matanuska Glacier, Alaska, USA. Journal of Glaciology, 41(137): 68-86.

ARCONE SA, SPIKES VB \& HAMILTON GS. 2005. Phase structure of radar stratigraphic horizons within Antarctic firn. Annals of Glaciology, 41(1): 10-16.

ARCONE SA, SPIKES VB, HAMILTON GS \& MAYEWSKI PA. 2004. Stratigraphic continuity in $400 \mathrm{MHz}$ short-pulse radar profiles of firn in West Antarctica. Annals of Glaciology, 39(1): 195-200.

BENTLEY CR, CLOUGH JW, JEZEK KC \& SHABTAIE S. 1979. Ice-thickness patterns and the dynamics of the Ross Ice Shelf, Antarctica. Journal of Glaciology, 24: 287-294.

BIRKELAND KW, JOHNSON RF \& SCHMIDT DS. 1998. Near-surface faceted crystals formed by diurnal recrystallization: A Case study of weak layer formation in the mountain snowpack and its contribution to snow avalanches. Arctic and Alpine Research, 30(2): 200-204. doi: 10.1080/00040851.1998.12002892.

CLARKE T \& BENTLEY C. 1994. High-resolution radar on Ice Stream B2, Antarctica: measurements of electromagnetic wave speed in firn and strain history from buried crevasses. Annals of Glaciology, 20(1): 153-159.

COLBECK SC. 1982. An overview of seasonal snow metamorphism. Reviews of Geophysics, 20(1): 45-61. doi: 10.1029/RG020i001p00045.

COLBECK SC. 1983. Theory of metamorphism of dry snow. Journal of Geophysical Research: Oceans, 88(C9): 5475-5482. doi: 10.1029/ JC088iC09p05475.

COLBECK SC. 1987. A review of the metamorphism and classification of seasonal snow cover crystals. IAHS Publication, 162: 3-24.

COLBECK SC. 1989. Snow crystal growth with varying surface temperatures and radiation penetration. Journal of Glaciology, 35: 23-39.

CUFFEY K \& PATERSON W. 2010. Physics of Glaciers. 4th ed., Elsevier Inc. Amsterdam. 704 pp.

DUNSE T, EISEN 0, HELM V, RACK W, STEINHAGE D \& PARRY V. 2008. Characteristics and small-scale variability of GPR signals and their relation to snow accumulation in Greenland's percolation zone. Journal of Glaciology, 54(185): 333-342. doi: 10.3189/002214308784886207.

EISEN 0, FREZZOTTI M, GENTHON C, ISAKSSON E, MAGAND 0, VAN DEN BROEKE MR, DIXON DA, EKAYKIN A, HOLMLUND P \& KAMEDA T. 2008. Ground-based measurements of spatial and temporal variability of snow accumulation in East Antarctica. Reviews of Geophysics, 46(2): 1-39.

GIANNOPOULOS A. 2005. Modelling ground penetrating radar by GprMax. Construction and Building Materials, 19(10): 755-762. doi: 10.1016/j.conbuildmat.2005.06.007.

HACHIKUBO A \& AKITAYA E. 1996. Surface hoar growing for several days. In: Proceedings of the International Snow Science Workshop in Banff. p. 86-90. Wiley Online Library.

HARPER JT \& BRADFORD JH. 2003. Snow stratigraphy over a uniform depositional surface: spatial variability and measurement tools. Cold Regions Science and Technology, 37(3): 289-298.

HELM V, RACK W, CULLEN R, NIENOW P, MAIR D, PARRY $\vee \&$ WINGHAM D. 2007. Winter accumulation in the percolation zone of Greenland measured by airborne radar altimeter. Geophysical Research Letters, 34(6): $1-4$.

HERRON MM \& LANGWAY Jr CC. 1980. Firn densification: an empirical model. Journal of Glaciology, 25: 373-385.

KOENIG LS, ALEXANDER PM, MACGREGOR JA, PADEN JD, FORSTER RR \& McCONNELL JR. 2016. Annual Greenland accumulation rates (2009-2012) from airborne snow radar. The Cryosphere, 10(4): 1739. 
KOVACS A, GOW AJ \& MOREY RM. 1995. The in-situ dielectric constant of polar firn revisited. Cold Regions Science and Technology, 23(3): 245-256.

KRUETZMANN N, RACK W, MCDONALD A \& GEORGE S. 2011. Snow accumulation and compaction derived from GPR data near Ross Island, Antarctica. The Cryosphere, 5(2): 391-404.

LIGTENBERG S, HELSEN M \& VAN DE BROEKE M. 2011. An improved semi-empirical model for the densification of Antarctic firn. The Cryosphere, 5(4): 809-819.

LOOYENGA H. 1965. Dielectric constants of heterogeneous mixtures. Physica, 31(3): 401-406.

LORRAIN P, CORSON DR \& LORRAIN F. 1988. Electromagnetic Fields and Waves. 3rd ed., New York: W H Freeman \& Co. 706 pp.

MEDLEY B, JOUGHIN I, DAS SB, STEIG EJ, CONWAY H, GOGINENI S, CRISCITIELLO AS, MCCONNELL JR, SMITH B \& BROEKE M. 2013. Airborne-radar and ice-core observations of annual snow accumulation over Thwaites Glacier, West Antarctica confirm the spatiotemporal variability of global and regional atmospheric models. Geophysical Research Letters, 40(14): 3649-3654.

MIÈGE C, FORSTER RR, BOX JE, BURGESS EW, MCCONNELL JR, PASTERIS DR \& SPIKES VB. 2013. Southeast Greenland high accumulation rates derived from firn cores and ground-penetrating radar. Annals of Glaciology, 54(63): 322-332.

MÜLLER K, SINISALO A, ANSCHÜTZ H, HAMRAN SE, HAGEN J0, McCONNELL JR \& PASTERIS DR. 2010. An $860 \mathrm{~km}$ surface mass-balance profile on the East Antarctic plateau derived by GPR. Annals of Glaciology, 51(55): 1-8.

PÄLLI A, KOHLER JC, ISAKSSONE, MOORE JC, PINGLOT JF, POHJOLA VA \& SAMUELSSON H. 2002. Spatial and temporal variability of snow accumulation using ground-penetrating radar and ice cores on a Svalbard glacier. Journal of Glaciology, 48(162): 417-424.

PARK C, MILLER R \& XIA J. 1998. Imaging dispersion curves of surface waves on multi-channel record. In: SEG Technical Program Expanded
Abstracts 1998. p. 1377-1380. Society of Exploration Geophysicists. doi: 10.1190/1.1820161.

POTOCKI M, MAYEWSKI PA, KURBATOV AV, SIMÕES JC, DIXON DA, GOODWIN I, CARLETON AM, HANDLEY MJ, JAÑA R \& KOROTKIKH EV. 2016. Recent increase in Antarctic Peninsula ice core uranium concentrations. Atmospheric Environment, 140: 381-385.

RICHARDSON-NÄSLUND C. 2004. Spatial characteristics of snow accumulation in Dronning Maud Land, Antarctica. Global and Planetary Change, 42(1-4): 31-43.

SHUMAN CA, ALLEY RB \& ANANDAKRISHNAN S. 1993. Characterization of a hoar-development episode using SSM/I brightness temperatures in the vicinity of the GISP2 site, Greenland. Annals of Glaciology, 17: 183-188. doi: 10.3189/S0260305500012817.

SPIKES VB, HAMILTON GS, ARCONE SA, KASPARI S \& MAYEWSKI PA. 2004. Variability in Accumulation Rates from GPR Profiling on the West Antarctic Plateau. Annals of Glaciology, 39: 238-244. doi: 10.3189/172756404781814393.

STROBBIA C \& CASSIANI G. 2007. Multilayer ground-penetrating radar guided waves in shallow soil layers for estimating soil water content. Geophysics, 72(4): J17-J29. doi: 10.1190/1.2716374.

THOMAS ER, MARSHALL GJ \& McCONNELL JR. 2008. A doubling in snow accumulation in the western Antarctic Peninsula since 1850. Geophysical Research Letters, 35(1): 1-5. doi: 10.1029/2007GL032529.

TRAVASSOS JM, PECHE LA \& SIMÕES JC. 2012. GPR events of temperate and cold land ice. Pesquisa Antártica Brasileira, Brazilian Academy of Sciences, 5: 137-151.

USGS - US Geological Survey. 2009. Landsat Image Mosaic of Antarctica (LIMA). Available on: <http://lima.usgs.gov>. Access on: February, 2014.

YILMAZ 0. 2001. Seismic Data Analysis: Processing, Inversion, and Interpretation of Seismic Data. 8801 South Yale Suite 500 Tulsa OK 74137 USA: SEG. URL http://link.aip.org/link/doi/10.1190/1. 9781560801580. $2027 \mathrm{pp}$ 